\title{
O TRATAMENTO DA INFORMAÇÃO NO ESPAÇO MUSEAL: \\ O MUSEU HISTÓRICO VISCONDE DE SÃO LEOPOLDO/RS E A COLEÇÃO FOTOGRÁFICA SESQUICENTENÁRIO DA IMIGRAÇÃO ALEMÃ
}

\author{
Daniela Schmitt ${ }^{*}$ \\ Universidade Feevale
}

\section{RESUMO:}

O estudo se dá no espaço do Museu Histórico Visconde de São Leopoldo/MHVSL. Verifica-se a importância da manifestação cultural referente às comemorações do Sesquicentenário da Imigração Alemã no país, em especial na cidade de São Leopoldo/RS. Estuda-se a coleção fotográfica que demonstra a dimensão do mesmo, além disso, examina-se a utilização da metodologia de documentação museológica durante o tratamento da informação nas fotografias.

PALAVRAS - CHAVE:

Museu Histórico Visconde de São Leopoldo, Sesquicentenário da Imigração Alemã, coleção fotográfica, memória, documentação museológica.

\begin{abstract}
:
The study occurs in Historical Museum Visconde of São Leopoldo.There is the importance of cultural expression referring to the celebration of the Sesquicentenary German Immigration in the country, especially in the city of São Leopoldo / RS. Studies to photographic collection which shows the dimension of the same, furthermore, it is examined whether the methodology of museum documentation is used during the systemization of photographs.
\end{abstract}

\section{KEY-WORDS:}

Historical Museum Visconde of São Leopoldo, Sesquicentenary German Immigration, photographic collection, memory, museum documentation.

I "Museóloga, mestranda em Processos e Manifestações Culturais pela Universidade Feevale. 
O tratamento da informação no espaço museal: o Museu Histórico Visconde de São Leopoldo/RS e a coleção fotográfica Sesquicentenário da Imigração Alemã

\section{Introdução}

A fotografia é uma importante fonte de pesquisa nas instituições museológicas. Visto a sua proeminência de interlocução entre museu e manifestação cultural, optou-se em abordar sua relevância como suporte de memória.

O trabalho se propõe a verificar a importância da coleção fotográfica intitulada "Sesquicentenário" relacionada às comemorações da imigração alemã no país. Analisa-se o tratamento que é dado ao acervo fotográfico do Museu Histórico Visconde de São Leopoldo a partir desta coleção, bem como acessar e interpretar o evento do Sesquicentenário na cidade de São Leopoldo.

Analisa-se o tratamento que é realizado pelo MHVSL e de que forma a documentação museológica é utilizada na coleção fotográfica e a forma como o Instituto Martius-Staden/SP, parceiro do Museu Histórico na digitalização das fotografias, participa do processo. A proposta é corroborar as ações da instituição e divulgar o seu espaço e acervo. Outros aspectos a serem considerados são: colocar em evidência o conjunto fotográfico e perceber a importância da sistematização da coleção.

Além disso, evidencia-se a disponibilização do acervo como processo fundamental para o acesso à pesquisa. A interação entre pesquisador e museu precisa ser incentivada, pois o museu deve ser explorado como fonte de pesquisa sobre os diferentes processos e manifestações culturais no contexto histórico-social do lugar em que esta inserido.

Este artigo tem como objetivo também uma reflexão sobre a metodologia utilizada pelos profissionais do Museu diante das ações de documentação museológica voltadas para a coleção fotográfica. Considera-se que o estudo de uma coleção específica mostre as possibilidades para adequarmos as estratégias de tratamento para as outras coleções fotográficas do Museu.

Para o desenvolvimento deste trabalho, o procedimento metodológico utilizado foi a pesquisa descritiva, com suporte bibliográfico. Parte-se do pressuposto teórico de Kossoy (2009) e Ferrez (1994), bem como de Catroga (2001). Acredita-se que os três autores fundamentem as reflexões aqui realizadas.

$\mathrm{O}$ estudo foi dividido em três momentos. No primeiro, apresenta-se a instituição museológica e a coleção fotográfica selecionada para a pesquisa. No segundo momento são discutidos os teóricos Borys Kosoy (2009), Fernado Catroga (200I) e Helena D. Ferrez (1994), no cruzamento com o objeto em questão: faz-se, portanto, uma leitura dos conceitos de fotografia, memória e documentação museológica, trabalhados pelos autores. Por fim, verifica-se na coleção fotográfica a maneira como é realizada a documentação museológica.

Não tendo a pretensão de dar uma fórmula ideal para a sistematização das coleções, este artigo almeja incentivar o diálogo entre os profissionais do Museu com o intuito de oferecer o tratamento ideal às suas coleções.

\section{O Museu Histórico Visconde de São Leopoldo e os festejos do Sesqui- centenário da Imigração Alemã}

O Museu Histórico Visconde de São Leopoldo resguarda importantes vestígios museológicos da imigração alemã. É uma entidade cultural privada, sem fins lucrativos, sustentado por sócios mantenedores. A instituição possui sede na cidade de São Leopoldo/RS ${ }^{2}$ onde desembarcaram 39 imigrantes vindos da

$\overline{2} \mathrm{O}$ primeiro núcleo de colonização alemã deu origem à Colônia de São Leopoldo, que recebeu este nome em homenagem à Imperatriz Leopoldina. 
Alemanha, no dia 25 de julho de 1824, contratados pelo Governo Imperial de D. Pedro I, dando início ao processo de imigração no país.

Segundo o historiador e idealizador do Museu, Thelmo Lauro Müller, os primeiros imigrantes passaram pelo Rio de Janeiro e chegaram a Porto Alegre em 18 de julho de 1824. Estes foram recepcionados pelo Presidente da Província, José Feliciano Fernandes Pinheiro, que os encaminhou para a antiga Real Feitoria do Linho-Cânhamo desativada, à margem esquerda do Rio dos Sinos. Pinheiro recebeu o título nobiliárquico de Visconde de São Leopoldo, dado por D. Pedro I.

O Visconde de São Leopoldo escreveu um livro intitulado Memórias no ano de 1840, onde descreve que um dos fatos mais importantes de sua administração foi à fundação da Colônia Alemã, por ser a primeira no Brasil. Por isso o Museu leva este nome, pois pertencera à pessoa que tornou possível a instalação da então colônia.

Em $I^{\circ}$ de abril de 1846, atendendo aos pedidos da população, São Leopoldo foi elevada à categoria de vila e desmembrada de Porto Alegre. Já em 12 de abril de 1864 a Lei $n^{\circ} 563$ a vila tornou-se cidade. A cidade recebeu o título de Berço da Imigração Alemã no Brasil no ano de 20 I I por meio da Lei I2.394, por ser considerada a primeira cidade a abrigar os imigrantes que em São Leopoldo/ RS se instalaram.

A criação do museu se deu pela vontade de construir um espaço onde fosse possível contar a história da imigração alemã.Além da comunidade, foram convidados os municípios que tiveram ligação com a Colônia Alemã de São Leopoldo: Campo Bom, Feliz, Montenegro, Nova Petrópolis, Novo Hamburgo, Rolante, Sapiranga, São Sebastião do Caí e Taquara.A sessão solene da fundação foi realizada na Prefeitura Municipal de São Leopoldo em 20 de setembro de 1959, criando-se o primeiro museu dedicado à imigração alemã no país.

Desde sua fundação o Museu Histórico Visconde de São Leopoldo vem recebendo doações de diferentes objetos e documentos. Devido ao trabalho realizado por mais de cinquenta anos, o Museu possui um dos acervos mais importante sobre a imigração alemã no Brasil. $O$ acervo tridimensional ultrapassa 35 mil peças; as fotografias somam em torno de 20 mil; os jornais totalizam cerca 360 títulos; grande parte em alemão, compreendidos num período de mais de cem anos.

O Museu possui, ainda, uma biblioteca que supera 20 mil livros - referentes à história do Rio Grande do Sul, da imigração alemã e de publicações da área dos museus entre outras. Conta com mais de 250 mil documentos. $O$ MHVSL recebe a colaboração de voluntários para a organização do seu acervo. Sua equipe é formada por três funcionários administrativos, um diretor, uma recepcionista, uma funcionária para serviços gerais e, ao longo dos anos, foram inúmeros os voluntários de diferentes instituições de pesquisa e ensino. Nos limites deste artigo, no entanto e como sublinhado na introdução, a análise recairá sobre o acervo fotográfico do Sesquicentenário da Imigração Alemã.

Além de ter sob sua guarda o acervo relacionado à imigração alemã e a história da cidade e da região, o Museu participa ativamente dos eventos relacionados a essas temáticas. O presidente e diretor do Museu, Germano Moehlecke e Thelmo Lauro Müller, respectivamente, foram membros, na cidade de São Leopoldo, da Comissão Executiva criada especialmente para os festejos que foram marcados por diversas comemorações sendo $\circ 25$ de julho o dia principal de festividades. 
O tratamento da informação no espaço museal: o Museu Histórico Visconde de São Leopoldo/RS e a coleção fotográfica Sesquicentenário da Imigração Alemã

Por ocasião da realização do Sesquicentenário da Imigração Alemã em 1974 e do Primeiro Centenário da Imigração Italiana em 1975, o Governo do Estado, por meio do decreto $\mathrm{n}^{\circ} 22.410$, tomou a iniciativa de instituir o Biênio da Colonização e Imigração.

O texto do então Deputado Victor Faccioni, Presidente da Comissão Coordenadora do Biênio da Colonização e Imigração, lembra que os imigrantes alemães por meio de sua personalidade e trabalho marcaram de forma positiva diversos setores da vida rio-grandense. A contribuição para o crescimento do Estado resultou na homenagem por meio de comemorações que visavam a exaltar o passado e projetar o futuro.

Um dos acontecimentos marcantes das comemorações foi a presença do Presidente da República, Gen. Ernesto Geisel, bem como de figuras de relevo da vida administrativa, cultural e social do Estado e do País, e personalidades vindas da República Federal da Alemanha, na data magna da imigração, 25 de julho. Estiveram nas cidades de Porto Alegre, São Leopoldo e Novo Hamburgo.

Foram inúmeras as reportagens de jornais e publicações referentes ao evento. No mesmo ano foi lançado o I Simpósio de História da Imigração e Colonização Alemã no Rio Grande do Sul, que ocorreu de 12 a 15 de setembro na cidade de São Leopoldo. De acordo com a historiadora Roswithia Weber (2013, p. II) "a retomada das festas, publicações e edições especiais sobre a imigração caracterizam um novo cenário, propício à reformulação identitária, em que o Museu atua de forma militante".

A compreensão e o conhecimento referente aos acontecimentos ligados ao Sesquicentenário da Imigração Alemã demonstram que ele foi uma forma de evocação das memórias, a partir das apresentações que fizeram parte da programação.A participação do Museu e de seus membros nos festejos confirma a busca da memória e da identidade vinculada aos antepassados.

Segundo Rockenbach e Flores,

Em 1974 ocorreu o Sesquicentenário da Imigração Alemã, uma oportunidade de retomada de valores esquecidos. Em meio às comemorações oficiais, surgiu uma dúzia de publicações relativas ao tema imigratório, entre eles o belo Álbum oficial do sesquicentenário da imigração alemã, bilíngue e em cores. (ROCKENBACH; FLORES, 2004, p. 6I)

O MHVSL tem sob sua guarda alguns exemplares do Álbum oficial do sesquicentenário da imigração alemã e grande parte das publicações relacionadas ao evento. Nesta, através de textos e fotografias a questão da presença germânica fica evidente. Lembra Weber, que

\footnotetext{
"o fortalecimento de vínculos étnicos e a demarcação da identidade étnica de imigrantes e descendentes de alemães são dados pela organização da festa, pelas histórias narradas, pelas vitrines montadas e por outros exemplos (WEBER, 2004, p. 46)
}

A criação de um lugar de memória e suas representações nos festejos do Sesquicentenário foram analisados através do "manifesto por imagens e discursos” (Pesavento, 1994) - fotografias - que permitiram uma definição da relevância da sistematização de uma coleção fotográfica relacionada ao maior evento já realizado relacionado à imigração alemã no país. 


\section{Fotografia, memória e documentação museológica}

Podemos dizer que a transmissão da memória de uma geração à outra pode ocorrer por meio dos chamados objetos culturais que se constituem como suportes de memória, neste caso, a fotografia.Assim, a partir de uma coleção fotográfica a pesquisa irá estudar a importância da informação no meio museal a fim de analisar o acervo do Museu Histórico Visconde de São Leopoldo.

De acordo com Ferrez (1994), os museus se preocupam com questões preservacionistas, de pesquisa e de comunicação, com as evidências materiais do homem e do seu meio ambiente, ou seja, seu patrimônio cultural e natural. Ferrez destaca que os objetos são veículos de informação, e que a partir da conservação e documentação é possível transformá-los em fontes para pesquisa científica e comunicação.

Por meio de fotografias é possível acessar um determinado contexto histórico-social em que as mesmas foram produzidas. Segundo Kossoy (2009) a sua existência é marcada por três estágios: a intenção, o ato do registro que trouxe à sua materialização e os caminhos percorridos por essa fotografia.

Entende-se a fotografia como suporte de memória, onde é possível, por meio da documentação museológica, estudar suas informações intrínsecas e extrínsecas, bem como toda sua dimensão como objeto/documento.

De acordo com Kossoy,

[...] as imagens representam um meio de conhecimento da cena passada e, portanto, uma possibilidade de resgate da memória visual do homem e do seu entorno sociocultural. Trata-se da fotografia enquanto instrumento de pesquisa, prestando-se à descoberta, análise e interpretação da vida histórica (KOSSOY, 2009, p. 55).

A imagem deve ser estudada e comparada, porém Kossoy (2009) salienta que ela é apenas um fragmento da realidade. Ou seja, ela é a percepção de quem registrou o momento.

apesar de ser a fotografia a própria "memória cristalizada", sua objetividade reside apenas nas aparências. Ocorre que essas imagens pouco ou nada informam ou emocionam àqueles que nada sabem do contexto histórico particular em que tais documentos se originaram (KOSSOY, 2009, p. I58)

Para isso, a documentação museológica é essencial para a recuperação da informação. É preciso extrair os símbolos do registro; só assim a imagem poderá contribuir para o desenvolvimento do conhecimento histórico.

Fotografia é memória e com ela se confunde. Fonte inesgotável de informação e emoção. Memória visual do mundo físico e natural, da vida individual e social. Registro que cristaliza, enquanto dura, a imagem - escolhida e refletida - de uma ínfima porção de espaço do mundo exterior (KOSSOY, 2009, p. 162).

Catroga (200I) trabalha com o conceito de metamemória. Ela "define as representações que o indivíduo faz da sua própria memória e o conhecimento que tem e afirma ter desse facto"(CATROGA, 200 I, p.43). Com isso, cabe à metamemória "o papel de acentuar as características inerentes à chamada memória social ou coletiva e às modalidades de sua construção e reprodução" (CATROGA, 200I, p. 44).

Ainda, segundo, Catroga:

A memória só poderá desempenhar a sua função social através de liturgias próprias, centradas em reavivamentos, que só os traços-vestígios do pretérito são capazes de provocar. Portanto, o seu conteúdo é inseparável dos seus campos de objectivação e de 
O tratamento da informação no espaço museal: o Museu Histórico Visconde de São Leopoldo/RS e a coleção fotográfica Sesquicentenário da Imigração Alemã

transmissão - linguagem, imagens, relíquias, lugares, escrita, monumentos - e dos ritos que o reproduzem. O que mostra que, nos indivíduos, não haverá memória colectiva sem suportes de memória ritualisticamente compartilhados. (CATROGA, 200 I, p. 48)

Assim, como é colocado pelo autor, para haver memória coletiva é preciso que se tenham os suportes de memória, no caso do museu, o objeto/documento. Já a pesquisa no museu amplia a possibilidade de comunicação dos bens culturais. Sendo focada na produção de conhecimento, ela garante uma visão crítica sobre determinados contextos e fatos dos quais o objeto é testemunho, ou seja, suporte de memória. "A pesquisa e a comunicação conferem sentido e atribuem uso social aos objetos, justificando, inclusive, a sua preservação" (JULIÃO, 2002, p.94).

Os museus permitem a mediação entre pesquisa e sociedade, oferecendo elementos à interpretação e a memória. Julião diz que o objetivo maior da pesquisa no museu:

[...] é preservar a possibilidade de acesso futuro às informações das quais os objetos são portadores. Para que o acesso a essas informações se efetive, é necessário que ocorra um processo de comunicação, no qual se estabelece uma relação entre o homem, sujeito que conhece, e o bem cultural, testemunho de uma dada realidade. (JULIÃO, 2006, p. 94)

Para que ocorra o desenvolvimento da pesquisa é preciso que os profissionais de museu tenham clara a importância da documentação museológica, pois será por meio dela que as informações do objeto/documento serão recuperadas "com o intuito de transformar o acervo museológico em fontes de informação em fontes de pesquisa científica ou em instrumentos de transmissão de conhecimento" (FERREZ, 1994, p. 64). A documentação museológica consiste, ainda, no processo de seleção, pesquisa, interpretação, organização, armazenamento, disseminação e disponibilização.

Segundo Novaes (2000, p. 44) "um museu que não possui suas coleções devidamente documentadas não poderá cumprir suas funções de gerador, comunicador e dinamizador de conhecimento junto ao patrimônio e à sociedade, enfim não será útil ao seu público". Sendo assim, afirma-se novamente que é fundamental que exista a recuperação e o tratamento da informação relacionada aos objetos/documentos.

De acordo com Padilha (20 I4, p. I0) "gerir e documentar o acervo museológico é o modo de legitimar a informação contida nos objetos e nas práticas da instituição. Essas atividades contribuem diretamente para as funções social, cultural e de pesquisa dos museus". Ou seja, o documento é a base que afirma algo a alguém, "ele é o meio que nos traz a informação e, assim, permite que o indivíduo produza conhecimentos diversos" (PADILHA, 20 I4, p. II)

Desta forma, ao considerarmos a teoria, partiremos para a coleção fotográfica "Sesquicentenário" do Museu Histórico Visconde de São Leopoldo. A ideia é a de verificar como está o processo de sistematização e, onde for necessário, sugerir adaptações no intuito de melhorar o acesso as informações.

\section{Sistematização da coleção fotográfica: Sesquicentenário da Imigra- ção Alemã}

Entende-se que a salvaguarda e organização da coleção fotográfica relativa a imigração alemã no MHVSL é fundamental para a comunidade da região. $O$ acervo fotográfico do Museu HistóricoVisconde de São Leopoldo se constitui em um pa- 
trimônio documental a ser preservado e consultado, na medida em que permite diferentes estudos sobre a história e a memória da imigração alemã no país, bem como da cidade de São Leopoldo. O acervo fotográfico contém em torno de 20 mil fotografias divididas em diferentes coleções. A coleção intitulada "Sesquicentenário" possui 25 fotografias 3; além dessas imagens encontramos no acervo tridimensional objetos relacionados ao Sesquicentenário da Imigração Alemã.

O Museu Visconde firmou parceria com o Instituto Martius-Staden/SP ${ }^{4}$ para o processo de digitalização. Desta forma as fotografias foram digitalizadas com o intuito de compartilhar as imagens entre as instituições de memória. Já a identificação foi realizada no espaço do Museu de forma voluntária por um estudante que na época cursava História. A ação ocorreu sob orientação dos responsáveis pelo Museu.

Não foi possível identificar a adoção de uma metodologia específica com relação ao tratamento da informação. Os dados estão disponibilizados por meio de uma folha impressa, como mostra a Figura I, junto a uma caixa de polionda onde ficam armazenadas as fotografias, bem como por meio digital, CD-ROMou computador disponível para consulentes, em arquivo word. Percebe-se que as informações são sucintas; apenas se descreve a imagem e é adotada uma numeração para cada fotografia.Além disso, apresenta o responsável pelo registro e a data.

Porém a numeração que é marcada no verso da fotografia difere do que esta no registro, como apresentado abaixo na Figura 2. A ausência de uma padronização pode atrapalhar a exatidão dos dados. É preciso estabelecer uma metodologia e adotar uma numeração padrão para todas as coleções. $O$ ideal é que exista uma identificação onde o objeto/documento em caso de roubo ou perda possa ser recuperado por meio da identificação relacionada ao nome da instituição a que pertence. Um exemplo seria a adoção do registro alfanumérico, em que é adotada a sigla do museu, neste caso MHVSL.

Percebe-se que a informação na ficha da Figura I é, em alguns casos, na verdade a inscrição contida no verso de cada fotografia, pois algumas contêm o dado “não há descrição". Não há uma diferenciação do que seriam descrição e o que seria inscrição. Neste caso, houve um equívoco na metodologia empregada.

As fotografias foram marcadas no canto inferior direito com lápis 6B, apresentado na Figura 2, e armazenadas em uma caixa de polionda. As inscrições no verso de cada fotografia não foram removidas. Isso facilitará a continuidade da recuperação das informações e da adoção da documentação museológica no espaço do Museu. Mesmo após a inserção das informações em ficha catalográfica e em banco de dados, será essencial que as informações permaneçam inscritas nas fotografias.

Além da digitalização, o trabalho de higienização também foi desenvolvido pelo Instituto Martius-Staden. Ficou evidente a preocupação com a segurança da coleção ao ser realizado o seu deslocamento até São Paulo. Entretanto, verifica-se a importância dessa ação ser realizada na própria instituição museal, pois o processo de documentação museológica é, ou deveria ser, responsabilidade do próprio Museu.

Cópias das fotografias digitalizadas se encontram na instituição e no Instituto Martius-Staden.Ao todo, até o momento, são 25 fotografias, além de outras coleções que totalizam em torno de 5 mil fotografias digitalizadas.

Ao sistematizar a coleção é possível uma pequena análise da fotografia.

3 Acredita-se que a coleção ultrapassa este número, porém é preciso organização dos processos de documentação, bem como de qualificação, a nível de gestão, da própria instituição.

4 O Instituto Martius-Staden de Ciências, Letras e Intercâmbio Cultural Brasileiro-Alemão é uma entidade de utilidade pública SM fins lucrativos, mantida pela Fundação Visconde de Porto Seguro. Foi criado em 1916, como uma associação de professores alemães. 
O tratamento da informação no espaço museal: o Museu Histórico Visconde de São Leopoldo/RS e a coleção fotográfica Sesquicentenário da Imigração Alemã

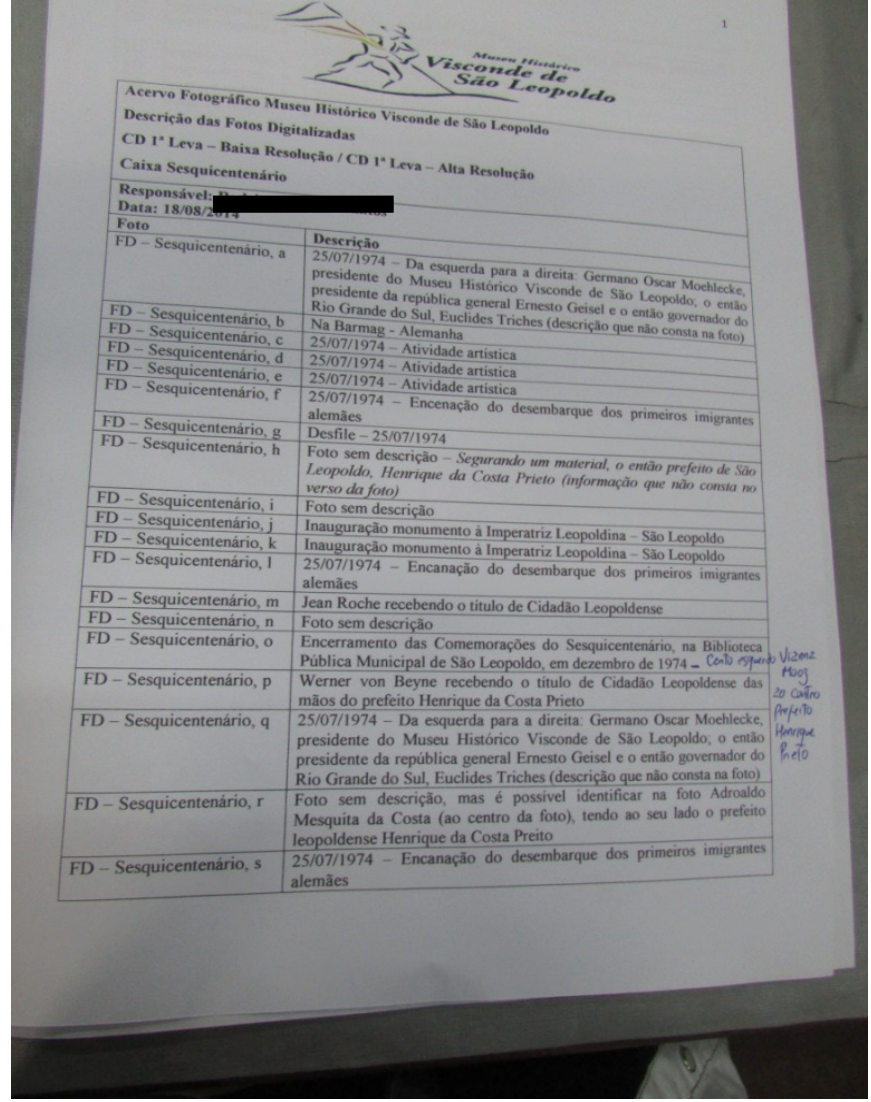

Figura I: Ficha para a descrição das fotografias digitalizadas.

Fonte: Museu Histórico Visconde de São Leopoldo.

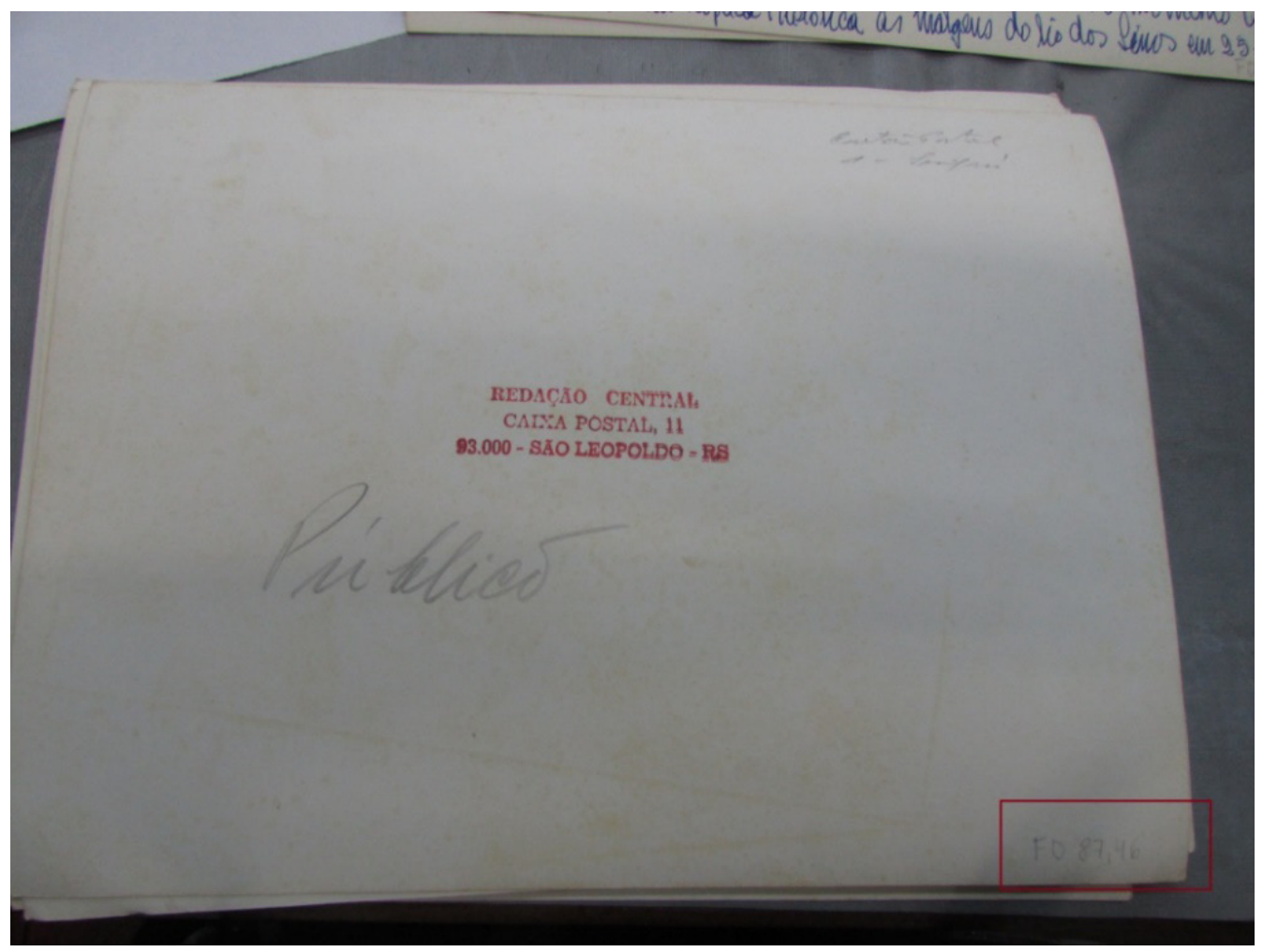

Fig. 02:Verso da fotografia com inscrições, no canto inferior direito esta a marcação com o número de registro FD.87.46.

Fonte: Museu Histórico Visconde de São Leopoldo. 


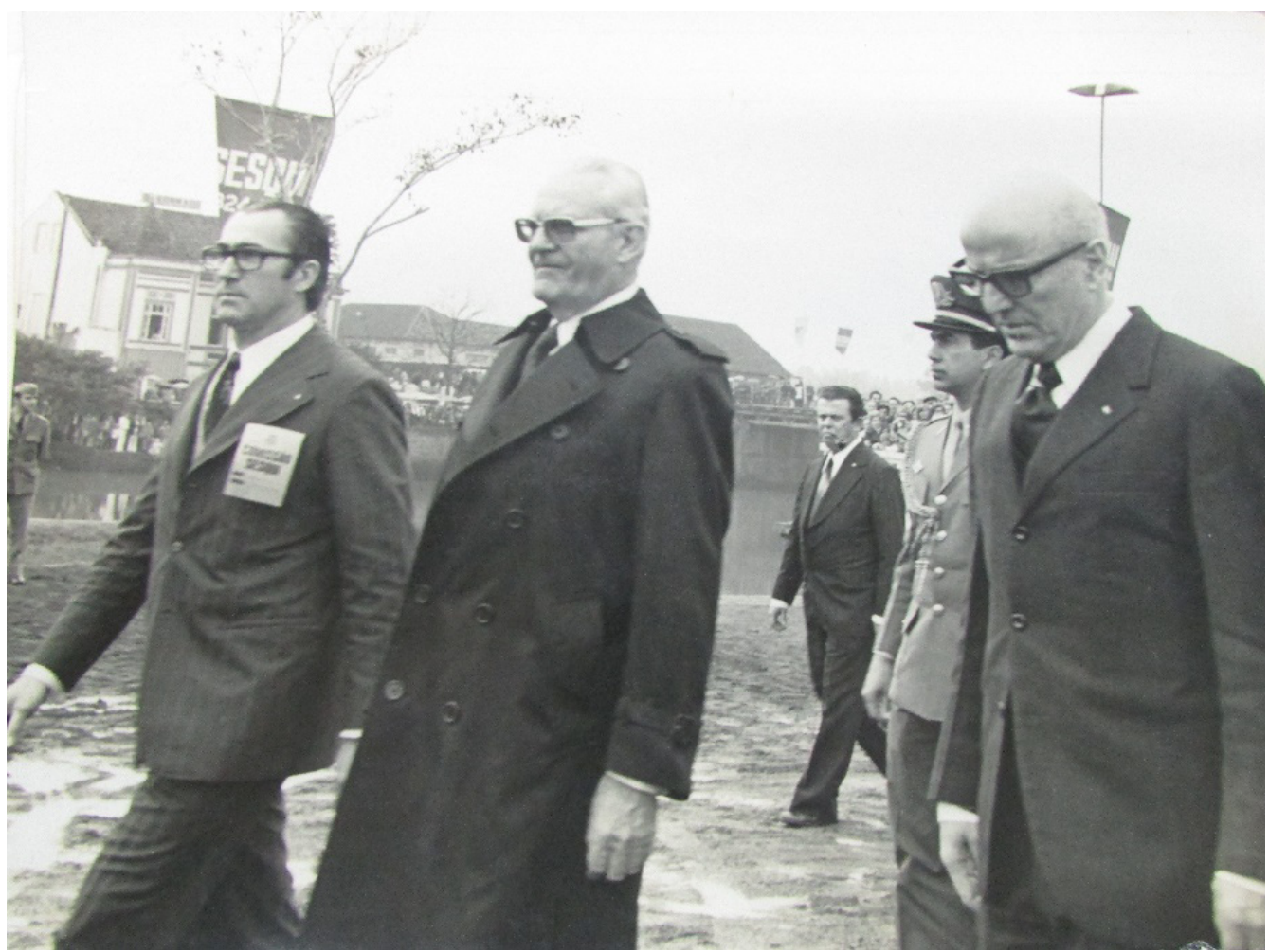

Figura 3: Germano Moehlecke, presidente do Museu e membro dos festejos do Sesquicentenário; o então presidente General Ernesto Geisel e o então governador do Rio Grande do Sul, Euclides Triches. Fonte: Museu Histórico Visconde de São Leopoldo.

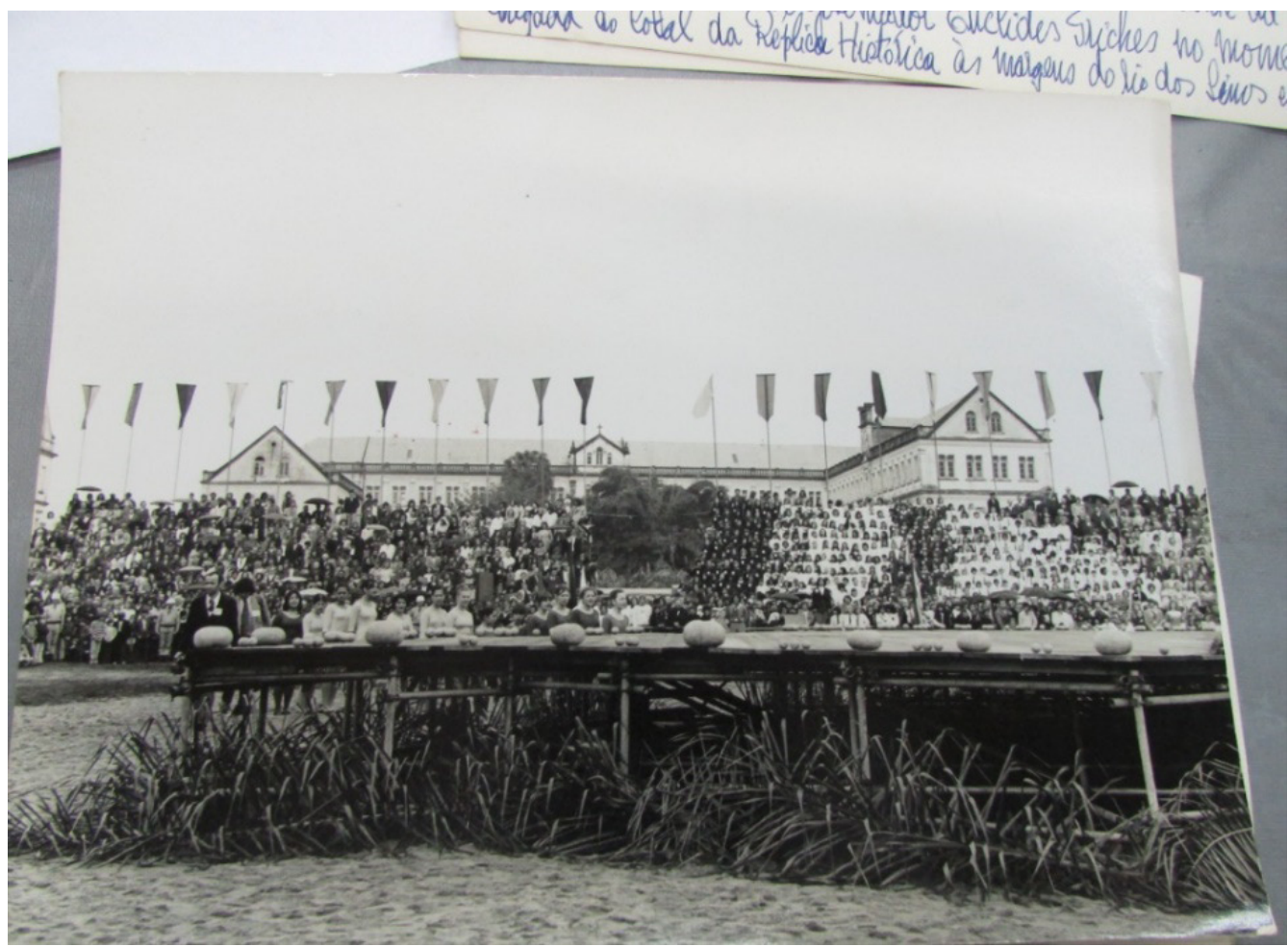

Figura 4: Palco para as apresentações das comemorações do Sesquicentenário da Imigração Alemã. Fonte: Museu Histórico Visconde de São Leopoldo. 
O tratamento da informação no espaço museal: o Museu Histórico Visconde de São Leopoldo/RS e a coleção fotográfica Sesquicentenário da Imigração Alemã

Porém, o processo de documentação museológica possibilitaria observações mais detalhadas das imagens e a percepção da enfática narrativa de uma manifestação cultural que marcou a história da cidade de São Leopoldo, como apontam as Figuras 3 e 4.

Verifica-se que a documentação museológica deve ser replicada em todas as coleções do Museu visto que é dever das instituições de memória manter seus acervos disponíveis ao público e aos pesquisadores.

Percebe-se na coleção fotográfica "Sesquicentenário" a dimensão de uma manifestação cultural que ocorreu no ano de 1974, uma coleção pequena comparada à dimensão do acervo fotográfico do Museu Histórico Visconde de São Leopoldo. Muitos historiadores desenvolveram e desenvolvem distintos estudos referentes ao evento comemorativo aos 150 anos da imigração alemã. Porém, a partir da adoção de uma metodologia e da disponibilização de diferentes coleções o Museu poderá ampliar o número de pesquisas que contribuam para a ressignificação do seu acervo museológico.

\section{Considerações finais}

A Política Nacional de Museus (BRASIL, 2003) apresenta o museu como ferramenta estratégica de aprimoramento dos processos democráticos para a valorização do patrimônio cultural. Estas considerações são pensadas no campo de políticas públicas de caráter mais amplo, onde os museus aparecem como instituições atreladas ao processo histórico e a serviço da sociedade.

A partir da orientação da Política Nacional de Museus, pode-se verificar a importância da criação do MHVSL na cidade de São Leopoldo e o seu papel importante na valorização do patrimônio cultural ao celebrar os 150 anos da Imigração Alemã.

Assim, a coleção fotográfica intitulada "Sesquicentenário" necessita passar por um processo de identificação. Os personagens que estiveram presentes nas comemorações devem ser contatados a fim de complementar as informações referentes a cada fotografia. É preciso, ainda, definir a sistematização padrão das coleções fotográficas sempre buscando o maior número de dados que auxiliem na pesquisa. Para isso, é essencial um trabalho voltado para a capacitação da equipe do Museu com ênfase na documentação museológica.

O Museu Histórico Visconde de São Leopoldo não possui um quadro técnico de funcionários que esteja direcionado para um programa de acervo. O trabalho que é realizado se dá por meio de voluntários, não técnicos, justificando a ausência de procedimentos direcionados a documentação museológica, bem como da falta de continuidade das ações. Porém, a instituição tem potencial para ampliar seu quadro técnico e possibilitar o melhor armazenamento das informações. Está sendo executado pelo Museu um projeto que foi contemplado pelo Fundo Municipal de Cultura da Prefeitura Municipal de São Leopoldo e que almeja colaborar a padronização e adoção da documentação museológica na instituição. $\bigcirc$ mesmo foi elaborado para uma coleção específica, com o intuito de replicá-lo nas demais. A partir disso, será adotado um banco de dados a fim de disponibilizar o acervo aos pesquisadores e ao público em geral.

Acredita-se que a adoção de um banco de dados será fundamental para a otimização do trabalho, bem como para a pesquisa. $O$ banco de dados assegurará a preservação do acervo fotográfico e de suas informações, além de contribuir com a alimentação contínua de informações. 


\section{Referências}

BRASIL. Ministério da Cultura. Política Nacional de Museus. Brasília, 2003.

CATROGA, Fernando. Memória e História. Fronteiras do milênio/ organizado por Sandra Jatay Pesavento. - Porto Alegre: Ed. Universidade/ UFRGS, 200 I.

FERREZ, Helena D. Documentação museológica: teoria para uma boa prática. In: Cadernos de ensaios, n. 2. Estudos de Museologia. Rio de Janeiro, Minc/lphan, 1994, p.64-73.

JULIÃO, Letícia. Pesquisa Histórica no museu. In: Caderno de Diretrizes Museológicas. Belo Horizonte: Secretaria do Estado da Cultura/Superintendência de Museus, 2002, p.93-105.

KOSSOY, Boris. Fotografia \& História. 2 ed. São Paulo:Ateliê Editorial, 2009.

NOVAES, Lourdes R. Da organização do Patrimônio Museológico: refletindo sobre documentação museológica. In: Museologia Social, SMC, Porto Alegre, 2000.

PADILHA, Renata C. Documentação Museológica e Gestão de Acervo. In: Coleção Estudos Museológicos, v.2. Florianópolis, FCC, 2014. 7I p.

PESAVENTO, Sandra J. Um Novo Olhar Sobre a Cidade: a nova história cultural e as representações do urbano. In: MAUCH, Cláudia et al. Porto Alegre na virada do século 19: cultura e sociedade. Porto Alegre/Canoas/São Leopoldo: Ed. Da Universidade/ UFRGS/Ed. ULBRA/ Ed. UNISINOS, 1994, I 36 p.

ROCKENBACH, Sílvio A.; FLORES, Hilda A, H. Imigração alemã: I 80 anos-história e cultura. Porto Alegre: CORAG, 2004.

WEBER, Roswithia. A CRIAÇÃO DE UM MUSEU DE IMIGRAÇÃO ALEMÃ NO PÓSNACIONALIZAÇÃO.Revista Memória em Rede, Pelotas, v.3, n.9.dez.20I3.

Artigo recebido em setembro de 2015.Aprovado em fevereiro de 2016 